\title{
La sociedad insustentable. Provisiones para una comprensión de las crisis contemporáneas, y las crisis de la sociología
}

\section{The unsustainable society. Provisions for a comprehension of contemporary crises and crises of sociology}

\author{
Ramón-Antonio Gutiérrez Palacios
}

Centro Mundial de Investigación para la Paz (CMIP-UPAZ) Montevideo, Uruguay

\begin{abstract}
RESUMEN. Las crisis son un problema perenne de la sociedad. En las crisis lo que está en crisis es la insuficiencia del modo de relacionarse las personas entre sí, y con los objetos de su cultura, para sustentar su asociación. Las crisis nos interrogan sobre la sustentabilidad social. Podríamos estar entrando en la tendencia hacia una crisis fundamental de insustentabilidad social global. Desde ella es interpelada la Ética de Sociedad. Queda abierta la pregunta: ¿Será posible la convivencia en la sociedad global crísica sin el pivote de una justicia global? Como efecto colateral e inevitable de las crisis, la sociología - y las ciencias sociales en su conjuntoenfrentan una crisis de sincronía teórica; respecto del saber y el comprender de las crisis de su tiempo en su tiempo.
\end{abstract}

Palabras clave: crisis social; ética de sociedad; sustentabilidad social.
ABSTRACT. The crises are a perennial problem of the society. In the crises, what is in crisis is the insufficiency in the way of being related people among if, and with the objects of their culture, to sustain their association. The crises interrogate us about the social sustainability. We could be entering in the tendency toward a fundamental crisis of global social unsustainability. From her, The Ethics of Society is interpellated. Thus, It remain open the question: Will be possible the coexistence in the global crises society, without the pivot of a global justice? As colateral and unavoidable effect of the crises, sociology and the social sciences, are facing a crisis of theoretical synchronization; regarding the knowledge and understanding of the crises of their time in their time.

Key words: ethics of society; social crisis; social sustainability.

\section{Introducción}

Las sociedades humanas no son hojas movidas por el viento. Sin embargo, transcurren en permanente estremecimiento desde su organización, desde su cultura, su territorio y su tiempo. Las sociedades humanas, no están allí arrojadas por sus dioses, a las fuerzas del destino, de tal suerte que de improviso algo igualmente misterioso y casual les sucede que dejan de ser o de estar. Tal como toda vida proviene de una preexistente, por elemental que ella sea, las sociedades se suceden a sí mismas, unas a otras, en complejida- 
des variables. Sin embargo las sociedades, como convivencia asociativa de vidas, suelen tener fin en su alteridad o, en las huellas remanentes de su aparente extinción. En ellas, sólo la persona activa como ser social, traslada y transmuta el ser social desde el obrar de su praxis histórica concreta. Las sociedades humanas no han estado nunca solas; por lejanos que sus territorios y arduas vías del pasado nos lo hicieran parecer. Ante todo, a cada sociedad la acompaña la historia de sucesiones de su propio ser social. En cursos de interacción social persistentes e intensos, como han sido los grandes procesos de colonización en el pasado, y como lo es hoy la expansión intensiva de los procesos de globalización tardía, las sociedades distinguibles, se limitan a sí mismas y amplían sus oportunidades y capacidades de viabilidad social; a la vez que inciden unas sobre otras en las posibilidades del conjunto. No hay predicción ni presagio factible que enunciar sobre cada sociedad, o respecto de las sociedades en sus encuentros. Pues, todo está en el devenir del ser social, y en el fortalecimiento de sus capacidades y posibilidades de ser, radica su solvencia vital para alcanzar las vías de sustentabilidad, que facultan su reproducción creativa mediante nuevos arreglos de convivencia. Toda vez que un sistema de personas tiende a perder sustentabilidad social enfrentará eventualmente una crisis social. Asimismo, ante cada crisis se ve reducida la sustentabilidad social. Por ello es que, para nosotros, el problema de la sociología es la insuficiencia de sociedad. Como efecto colateral de las crisis, la sociología - y las ciencias sociales en su conjunto- enfrentan una crisis de sincronía teórica; respecto de su solvencia científica y reflexiva para proporcionar el saber y el comprender de las crisis de su tiempo en su tiempo. En consecuencia, las crisis aparecen como una interpelación teórica a la sociología y las ciencias sociales y —a la vez que reponen la presión ética de «abrir las ciencias sociales» ${ }^{\perp-}$, exponen una demanda práctica de aplicación; cuya plena satisfacción factible todavía parece, sin embargo, lejana.

Admitimos la posibilidad de conocer y explicar teóricamente las crisis sociales contemporáneas; por cuanto las concebimos como hechos reales en sus manifestaciones. Si la realidad son los modos de construirse la materialidad del universo en su operar y, en ella descansan todas las posibilidades de ser y de hacer de lo humano quien, a su vez, es un componente de dicha realidad en su fisicalidad e idealidad. Entonces, entendemos que es posible, asimismo, una reflexión del pensar comprensivo sobre dicho saber de la realidad de las crisis, y sus implicaciones para el obrar de la praxis social humana. Ya que: «La comprensión precede y prolonga el conocimiento. La comprensión preliminar, base de todo conocimiento, y la verdadera comprensión, que lo trasciende, tienen en común el hecho de dar sentido al conocimiento.» (Hannah Arendt, 2005: 33). En efecto, nos mueve aquí una inten-

${ }^{1}$ Como se advertirá, ésta es una referencia al documento (1996) Abrir las ciencias sociales. Informe de la Comisión Gulbenkian para la reestructuración de las ciencias sociales. Ediciones Siglo XXI-CIICH-UNAM, México. 
ción mucho más vital que estrictamente racional. No vamos tras verdad alguna, sino en una búsqueda de sentido; de lo que se nos aparece como una tendencia crísica ${ }^{2}$ fundamental de la existencia contemporánea de lo humano. En este sentido, si se quiere, lo que hacemos es transitar por una senda teorética pre-sociológica; toda vez que no pretendemos postular aquí una «teoría científica» (M. Bunge, 1999:144). Esta ulterior intención, debería llevar a conocer y explicar los mecanismos sociales generadores de las crisis como un requisito imprescindible para su incorporación teórica cognitiva, y posibilitar así una posterior comprensión y expansión de la visión teórica de las crisis en sus diferencias. Este último camino, de comprensión reflexiva, habida cuenta de que es un proceso continuo del pensar, es el que emprendemos aquí.

En las líneas que siguen, no hacemos una revisión bibliográfica de la persistencia teórica de la ocupación, sociológica o de las ciencias sociales, respecto de las crisis. Más bien, asumiendo el riesgo, y en la esperanza de no generar con ello una otra crisis, inducida quizá por nuestra heterodoxia, intentamos poner una perspectiva de sentido del lugar actual de las crisis contemporáneas, y postulamos una tesis intuitiva de las crisis, que a nuestro temerario juicio, se nos aparecen como un proceso tendencial de reducción histórica. El supuesto que subyace aquí es que del conocimiento y comprensión de las crisis, es posible aprender algo que nos lleve a entender, también, las crisis de la sociología y de las ciencias sociales. Y, a partir de ese punto, dejar abierta la invitación a un nuevo pensamiento sobre las crisis; que promueva la búsqueda de sus explicaciones cognitivas así como de su permanente pensar comprensivo. En consecuencia, señalaremos algunas interrogantes trazadoras, e intentamos argumentar limitadamente en torno a la tesis propuesta. Cumpliremos así con proporcionar algunas provisiones para el viaje de una travesía aventurera, que presentimos más larga y tenaz, y que debiera proporcionarnos algunas cartas de navegación para no zozobrar en mares crísicos.

\section{La sustentabilidad social y sus crisis en la historia}

La Historia Social Humana, es la historia de la discontinuidad de la suficiencia de sociedad para contribuir a la expansión de las capacidades ${ }^{3}$ de ser y del hacer humanos; como personas individuales, y como asociaciones de

${ }^{2}$ Al emplear esta palabra, nos asiste la intención de reducir la connotación negativa de la palabra «crítica» que, adicionalmente, refiere también a otro significante fuerte en sociología denotado mediante el verbo «criticar».

${ }^{3}$ Cual sea la «lista» de esas capacidades, definida como pertinente, para la «...expansión de las "capacidades" de las personas para llevar el tipo de vida que valoran y que tienen razones para valorar». Amartya Sen. (2000:34). 
personas de conformación voluntaria y autónoma. La Historia Social Humana, es la historia de los desafíos para expandir la libertad sin renunciar a la justicia en la convivencia. Por ello es que observamos una recurrencia de conflictos y de crisis que se enlazan en un continuo que solamente parece romperse cuando la sociedad misma se hace insuficiente, y abre paso a la catástrofe social y al caos que precede su extinción. Nada en la Historia Social Humana parece evidenciar que sean fuerzas externas, ajenas al propio obrar de la praxis social humana, las causas cruciales eficientes de extinción de población humana alguna. Más bien las causas externas, como factores generadores de crisis, han presentado desafíos que la humanidad ha podido superar hasta ahora. Por otra parte, sin embargo, no parece haber argumentos y evidencias razonables, que nos permitan prever que las sociedades humanas no podrán seguir teniendo éxito relativo en el futuro.

Sin embargo, la principal dificultad para conceptualizar lo que es sustentabilidad, deriva del hecho de que empezamos a usar la palabra mucho antes de que la teoría pudiera otorgarle un contenido preciso. El problema no solamente ha surgido de la ambigüedad de las definiciones, sino sobre todo desde la perspectiva definicional adoptada. Como suele suceder, también en la ciencia, ello llevó a un innumerable juego de improvisaciones, y ajustes sucesivos. Brevemente, permítanos el lector esta necesaria revisión terminológica. Ante todo hay que decir, que usualmente olvidamos por obvia, la raíz elemental de la palabra sustentabilidad: la noción de sostener. Una fuente 4 , accesible al alcance de todos, nos dice al respecto: «Sostener / [sustenir] 1. Soportar, sostener el peso de; 2. Mantener arriba, seguir llevando; 3.Mantener o conservar con vida; 4. Experimentar, padecer; 5. Elevar por encima, alentar, confortar; 7. Confirmar, ratificar; 8. Sostener como válido. // SYN soportar, nutrir, alentar». De lo anterior, se puede llegar a concluir que lo que sostiene la vida es la naturaleza; biótica y abiótica. Así un medio ambiente sin intervención humana, como proponían los ecologistas integrales (S. M. Lélé, 1991), nos permitiría reconocer el estado preciso de sustentabilidad ecológica de los sistemas naturales. En consecuencia, mientras mayor sea la intervención humana, menor sería la sustentabilidad. El principal problema es que técnicamente la medición resulta irrealizable. Sobre todo porque, es escasa, por no decir que inexistente, la porción de naturaleza terrestre que no haya sido afectada en alguna medida, directa o colateral, por la acción humana ${ }^{5}$. Asimismo, una noción de sustentabilidad, a partir de que la naturaleza se sostiene sobre sí misma, olvida que la naturaleza es aleatoria y caótica desde su legalidad, y que también incluye ciclos naturales de degradación, mutación, y recreación constantes. Actualmente, la física admite tam-

${ }^{4}$ The Scribner-Bantam English Dictionary.(1985). Bantam Books, New York, p. 918.

${ }^{5}$ No sucede lo mismo si nos referimos a la exploración e investigación de la naturaleza del planeta. 
bién la posibilidad teórica de una antinaturaleza. Por otra parte, el olvido principal, está en el ser humano como ente bioantropológico, como naturaleza compleja de la naturaleza, y único ser conocido capaz de «desnaturalizarla» ad extremis artificialis ${ }^{6}$. En efecto, precisamente lo que las sociedades humanas intentan, sin lograrlo del todo, es interrumpir las tendencias caóticas y entrópicas de la naturaleza. Por ello, quizá la principal contribución de las ciencias sociales a la comprensión de la naturaleza humana, sea el hecho de concebir a los seres humanos como: seres que se constituyen a sí mismos en su relación asociativa con otros de la misma especie. Los seres humanos somos tales en tanto constituimos sociedad; fuera de la sociedad perdemos nuestra Humanidad. Esta dependencia, o interdependencia vital, es natural en tanto construcción cultural humana. Así, se ha señalado que: «El sistema Homo es una realidad "trinitaria" cuyos términos son inseparables porque son interdependientes unos de otros. El problema central es el de la organización naciendo, manteniéndose y desarrollándose en la interacción de estos términos, constituyendo sistema o unidad compleja: es éste sistema "trinitario" el que hemos de llamar hombre y no tal aspecto parcial (el individuo, la especie, la sociedad). El hombre, es biocultural por naturaleza, no se define alternativamente por referencia corporal o cultural; se define de forma “total” biopsicosocial» (Edgar Morin,1978:57). Las sociedades están incrustadas en la naturaleza, y se funden con ella en cada una de las personas individuales. La naturaleza no puede zafarse de la sociedad. El ser humano es la interfaz cultural de la naturaleza.

Sustentabilidad, en términos generales, es el atributo emergente de la facultad de construir viabilidad del proceso vital en cualquier sistema vivo. Por su parte, y ya que los sistemas sociales humanos incorporan la intencionalidad como propiedad de su ser social, la sustentabilidad es una propiedad dinámica emergente, que solamente puede ser construida conscientemente, en y desde la intencionalidad social, por el Homo Socialis. En efecto, sustentar la viabilidad de un sistema de vida social humano en sus capacidades para ser, trae consigo la idea de bien; es decir, la idea misma de sustentabilidad, es una noción ética del bien buscado por el querer de la voluntad de ser humanos en asociación con otros. Volveremos, más adelante, sobre este aspecto.

Pero, entonces: ¿Qué sostiene a la sociedad?? ${ }^{7}$ Desde luego, existe una relación de correspondencia - desde la interfaz cultural de la naturalezaentre sustentabilidad social y sustentabilidad ambiental, sin embargo, ambos

${ }^{6}$ Para oportuna conveniencia de lo señalado aquí, en estos días acaba de ser anunciada publicamente la «creación» de la primera célula elaborada mediante procedimientos sintéticos artificiales.

${ }^{7}$ Intentamos aquí plantear, desde otra perspectiva, quizá complementaria, la interrogante formulada por Elster como: ¿Qué es lo que mantiene unidas a las sociedades y les impide desintegrarse en el caos y en la guerra? (Jon Elster, 2006:13). 
conceptos se refieren a dimensiones diferentes, que se contienen, en un mismo proceso y tiempo. Ya que, no hay sustentabilidad ambiental sin sustentabilidad social. La sustentabilidad social no es alguna simplificada combinación de desarrollo económico, equidad social y sustentabilidad ambiental. Un acercamiento intuitivo al concepto de sustentabilidad social lleva a considerar que: todo proceso o encadenamiento de acciones sociales, tales como aquéllas que forman los programas de desarrollo y las políticas públicas, así como los proyectos privados asociativos, no deberían llegar a producir desde su intencionalidad - consecuencias que sean socialmente reductivas o ambientalmente destructivas.

Así, por ejemplo, los «despidos masivos» son siempre socialmente reductivos, no solamente porque incrementan el paro (desempleo), o porque de hecho reducen la demanda agregada, afectando todo el flujo circular de la economía, sino porque rompen la asociación de las personas afectadas, y realimentan el ciclo perverso de la insuficiencia de sociedad; que impide, difiere o traslada las posibilidades efectivas de resolver los problemas de la crisis económica, sus impactos sociales y efectos mediatos propiamente económicos. Además, para que exista sustentabilidad social, las acciones emprendidas deben realizar todos los esfuerzos para proteger a quienes son vulnerables; tanto en el «punto de partida» como de aquéllos que devienen en tales durante el curso del desenvolvimiento social. Asimismo, habrá de atenderse a las particularidades de la diversidad, y a la situación de contexto. La sustentabilidad social, depende tanto de las condiciones institucionales del contexto de la acción, como de las particularidades de la ética de sociedad. Por ello, la búsqueda de participación social pertinente, en los procesos de toma de decisión y ejecución, como tal expresión de expansión democrática, aparece como uno de los requisito de la gobernanza y gobernabilidad sociales; rasgos éstos que son propios de la sustentabilidad social. En consecuencia, todo proceso socialmente sustentable, incrementará el capital social positivo, la viabilidad social de las personas, individuales y asociativas, y del sistema social en su conjunto a la vez que, aumentará la densidad cultural y, la creatividad social para asegurar su mayor flexibilidad de autoorganización. En todo ello juegan un papel central los procesos de comunicación de la sociedad y de construcción de consensos. De este modo, la sustentabilidad social es reflejo de la capacidad colectiva para reorganizarse desde la convivencia social, asimilando creativamente las fuerzas destructivas que, eventualmente, surgen de las crisis, sectoriales o sistémicas, del conflicto descanalizado y de la disociación de las violencias. Así, la sustentabilidad social, es un atributo de la sociedad para responder con eficacia imaginativa ante los desafíos emergentes. Desde el punto de vista de su filosofía moral, la sustentabilidad social emplea la virtud de justicia como su eje generador y ordenador cardinal. Por extensión, también hablamos de justicia global. Pero, asimismo, se requiere reconstruir permanentemente un 
balance constructivo entre virtudes cívicas y valores personales. Sobre todo porque, «Los valores en una sociedad pluralista aspiran a contar con un centro de consenso y una periferia de disenso inherente a diferentes visiones del mundo que conviven en una sociedad democrática» (Gustavo Pereira, 2004:273). Por otra parte, y dado que la sustentabilidad social es un fenómeno observable, es susceptible de explicación y comprensión. Puede hablarse, entonces, de grados y modos (estilos) de sustentabilidad social. La noción de sustentabilidad social involucra el principio de que: al ser la sociabilidad y la convivencia asociativa el modo vital de existencia humanos, es necesario preservar y expandir las condiciones y oportunidades de reproducir creativamente esas modalidades de convivencia, atendiendo a las posibles formas de reorganizarse para incrementar su viabilidad; en el concierto de convivencia con otros. En resumen: Un grupo humano será socialmente sustentable, si existe como un modo de organización asociativa que permita su reproducción creativa en libertad, capaz de reducir sus tendencias de insuficiencia social, a través de un procedimiento normativo de justicia distributiva, y de convertir los procesos de crisis y conflicto en oportunidades para su reorganización; siempre en referencia a otras sociedades humanas, que están en su curso de interacción, y a la naturaleza extensiva. En definitiva, una sociedad sustentable es capaz de proveer y de garantizar una calidad de vida decente, para las generaciones presentes y futuras; habida cuenta de los factores incontrolados de la naturaleza y, de aquellas amenazas que provengan de otras sociedades, excluidas por otras, o autoexcluidas de los procesos de búsqueda de viabilidad y sustentabilidad social en referencia a los otros. Siempre es posible adquirir sustentabilidad social relativa «a costa de otros», y depredando la naturaleza extensiva. En efecto, es lo que preferentemente hemos venido haciendo. De ello dan amplio testimonio las experiencias de colonización, esclavismo y vasallaje. Sin embargo, dicha sustentabilidad, buscada y obtenida sin tener en cuenta a los otros, y por largos que sean sus periodos de «dominación», desde la Historia, se ha demostrado su inevitable declinación y decadencia. Así entonces, no aparece como necesario el tener que aguardar a que todas las sociedades sean sustentables socialmente; para emprender las tareas de diseño institucional y habilitación ética de las capacidades para serlo. Aunque la sustentabilidad social es históricamente variable, en función de las tendencias y crisis de reducción de suficiencia social, requerimos de mecanismos sociales que promuevan tendencialmente la sustentabilidad social permanente. Además —al menos desde el punto de vista teórico-, tampoco parece ser un prerrequisito indispensable la «sustentabilidad social global»; para desplegar la voluntad de búsqueda de sustentabilidad social para una sociedad en particular. Como ya señalamos más arriba, la sustentabilidad social es una propiedad dinámica emergente. No es un fenómeno de «generación espontánea». La sustentabilidad social es un proceso producido por la praxis del obrar asociativo 
intencional. Obedece a una selección entre opciones, y a la ejecución de acciones que son el resultado de decisiones; también intencionales. En consecuencia, la sustentabilidad social es el producto de una Ética de Sociedad Sustentable (EdSS).

\section{3. Ética de Sociedad y Sustentabilidad Social}

Entendemos por Ética de Sociedad (EdS), al sistema de juicios que otorgan sentido, asignan valores, definen costumbres y fijan reglas a la vida activa observada y, que de hecho han sido adoptados por la gran mayoría de las personas individuales y asociativas (organizaciones) de una sociedad concreta. En general, lo que nos enseña la Ética de Sociedad observada, es que no es necesario resignase a vivir en el riesgo permanente de una insuficiencia social crísica. No parece éticamente aceptable ni prácticamente pertinente el condenar a millones de seres humanos a la pobreza y las desigualdades. Tampoco parece éticamente pertinente resolver, crisis particulares, sin atender a las consecuencias que dichas soluciones acarrean para la sustentabilidad social. El querer ético de la libertad siempre es posible como voluntad efectiva. Junto a ello, aparece como una exigencia pertinente: «la necesidad de establecer las bases de una teoría de justicia distributiva que bajo los supuestos de igualdad, solidaridad y reconocimiento recíproco pueda enfrentar estas dificultades, en principio a nivel local y luego a nivel global» (Gustavo Pereira, 2007:13-14). No somos prisioneros de nuestro comportamiento mal intencionado. Si bien hay límites para ejercer el libre albedrío, muchos de esos límites dicen relación con las posibilidades de sustentabilidad social. Mientras menor es la disponibilidad de libertad de las personas individuales, la sociedad tiende a ser menos sustentable: sufren las personas, y sufre la naturaleza. Mientras mayor es la libertad de las personas individuales, la sociedad no tiende a una mayor sustentabilidad, sino a su desarticulación y desvinculación: las personas pierden humanidad, y la naturaleza podría perderse con ellas. Lo que podría - pues aún carecemos de ella-, mantener unida a una sociedad, y posibilitar su evolución nutricia con otras sociedades y la naturaleza, es la existencia de una Ética de Sociedad Sustentable (EdSS). Una sociedad más sustentable, puede ser más libre si la libertad es un bien de libre tránsito, y que todos estamos dispuestos a otorgarnos unos a otros. Por ello, quizá el desafío de imaginar una nueva ética asociativa, que promueva la sustentabilidad de la sociedad desde sí misma, y en armonía con su medio ambiente, requerirá facilitar el paso siguiente en la evolución de la especie humana; en una clara dirección de expansión de su pensamiento. Sin duda, esta labor nos exige adoptar una mirada flexible, que busque un balance dinámico, cambiante, de la sustentabilidad sobre el problemático continuo de «compromiso y distanciamiento». Lo cual repone la pregunta: «¿Es posi- 
ble encontrar, por lo menos sumariamente, criterios para determinar los diversos grados de compromiso y distanciamiento? ¿Qué significa realmente, qué implica decir que en sociedades como la nuestra, con un grado de industrialización y un dominio sobre las fuerzas no humanas de la naturaleza relativamente elevados, esta "naturaleza" suele ser percibida con menor compromiso, es decir con mayor distanciamiento, que la "sociedad"?» (Norbert Elias, 2002:22). La relevancia de esto radica en que, el eje organizador de parte importante de las crisis contemporáneas, es la incorporación no discriminante y consumista de la naturaleza como insumo social; sin comprender el lazo de continuidad que existe entre humanidad y naturalidad. Si hay algo que la historia de la modernidad y sus crisis han puesto en evidencia, es que no es la lucha por la dominación de la naturaleza la que puede rendir frutos a la humanidad, sino la de avanzar en un estadio evolutivo que posibilite la dominación de la cultura humana ${ }^{8}$ para conformar sociedades sustentables. Así entonces, podrían ser disímiles las respuestas a la pregunta: ¿estamos en una «era de interés propio»? (Peter Singer,2007). ¿No podría ser, su respuesta afirmativa, una percepción que se tiene desde ciertas posiciones de la sociedad? ¿o desde ciertas sociedades particulares de occidente? Si bien puede considerarse factible, para occidente, la presencia de una relativa hegemonía cultural del interés propio; parece evidente que no todos tienen el poder suficiente para hacer prevalecer su interés propio. Tampoco es menos cierto que la principal razón de por qué perduran las sociedades, en medio de fuerzas desestabilizadoras y de las actuales catástrofes naturales, e intensidad de crisis recurrentes, es porque todas ellas son portadoras de una Ética de Sociedad que, contra todo, promueve cooperación, solidaridad y resiliencia. Nuevamente aquí es válida la recomendación de Elías. Sobretodo, para prevenirnos de la observación ingenua o sesgada.

Si la ética señala un camino de que no todo vale por igual, entonces, el futuro posible de la vida, y de los sistemas sociales humanos en ella, requiere de decisiones libres; que informen sobre la ética del tipo de sociedad global que queremos. Sin embargo, hay aquí un supuesto teórico desde el cual partimos. Y, es que: los mundos posibles, solamente pueden serlo a condición de ser socialmente sustentables. Y, pueden serlo, dado que la Ética de Sociedad es una expresión real concreta de la praxis colectiva. Siempre habrá en toda sociedad humana una Ética de Sociedad, prevalesciente; sujeta a las posibilidades de acción de cambio de los agentes. Si no hay acción de cambio intencional, orientada a la sustentabilidad, entonces, puede que prevalezca un Modelo de Insumo de Deseos (todo deseo de novedad sirve para transformarse en «el objeto de mis - "nuevos"- deseos»; con el sólo límite de la tecnología disponible) y, entonces, la catástrofe social sería inevitable. La estupidez se impondría a la sensatez. Pero, y es lo importante,

${ }^{8}$ Por esto es que la ética de las tecnologías se ha hecho relevante en nuestros días. 
la existencia de una Ética de Sociedad Insustentable (EdSI), no es una necesidad del sistema. En cambio, la existencia de una Ética de Sociedad Sustentable (EdSS), sí es un imperativo de la mantención del sistema (y de su identidad), así como del incremento de su viabilidad. La Ética de Sociedad no cambia porque cambie la distribución social de la «bondad espiritual» de las personas, sino porque existen unas condiciones de contextos de acción pertinentes, que pueden activar algún mecanismo social, que promueva modalidades de transición hacia una mayor sustentabilidad del sistema. Descubrir dicho mecanismo - que combina razones, emociones, normas y creencias-, es la tarea de las ciencias sociales ocupadas en el objeto de estudio de la ética de sociedad y las crisis de sustentabilidad social. Adicionalmente, en la búsqueda de soluciones a las crisis, parece crucial la comprensión crítica del saber sobre las crisis de insuficiencia e insustentabilidad sociales. Y, «Una tal crítica se hace posible por el hecho de que en tales soluciones de problemas suelen estar contenidas ideas sobre contextos reales que ya no corresponden al nivel actual de conocimiento» (Hans Albert, 2002:135). Surge así con ello, el requisito de buscar una correspondencia sincrónica del saber de la crisis desde su actualidad teórica.

\section{4. ¿Qué (creemos) saber sobre las crisis?}

4.1. Qué saber tenemos y hemos de adquirir sobre las crisis, y qué saber creemos tener son cuestiones diferentes, pero interdependientes. Desde la sociología, y algunas otras ciencias sociales, sobre todo desde la ciencia política, se ha escrito y dicho mucho sobre las crisis. Sin embargo, como otras teorías sociales especiales, la Teoría Social de las Crisis, está todavía lejos de cumplir su promesa explicativa. La sociología de las crisis no se ocupa de todas las crisis, sino de aquéllas que son pertinentes a su problema de conocimiento, aquél que hemos enunciado como insuficiencia de sociedad. Así, toda crisis que amenace las posibilidades de expansión del ser social y su sustentabilidad asociativa; será materia de interés de la sociología de las crisis. La interrogante, instigadora de la investigación, entonces será: ¿Qué saber necesitamos para distinguir — cuándo, cómo y por qué- una sociedad genera una crisis de insuficiencia social que tiende a reducir drásticamente su sustentabilidad social?

4.2. Curiosamente, y salvo honrosas excepciones ${ }^{9}$, la mayoría de las veces, el concepto mismo de crisis ha quedado sobreentendido ${ }^{10} \mathrm{o}$, sin con-

${ }^{9}$ Por ejemplo, las valiosas contribuciones de Georges Balandier (1994) en El desorden. Gedisa, Barcelona. Y, Nicolás Tenzer (1991) en La sociedad despolitizada. Paidós, Buenos Aires.

${ }_{10}$ Tal como parece ser, y a modo de ejemplo entre muchos, el caso del estudio de Gabriel A. Almond, Scott G. Flanagan y Robert Mundt (1973) en Crisis, Choice and Change: Historical studies of political development. Little Brown, Boston. 
tenido; diluyéndose en la polisemia habitual de nuestro lenguaje disciplinario. Por otra parte, y como descargo, existe una justificación empírica de la polisemia observable en el concepto de crisis, y ella proviene del hecho de que las crisis suelen tener diferentes núcleos o ejes de articulación, que actúan como factores desencadenantes, y de otros alternos que emergen como desactivadores o recreadores de las crisis. Todas las crisis no son la misma crisis, y cada crisis en una expresión histórica concreta de sus causas y contextos de acción. Nosotros, afirmaremos aquí que: estamos frente a una crisis en la sociedad toda vez que observamos una insuficiencia social que se expresa como reducción del operar de su realidad relacional (Frédéric Vandenberghe, 2007); en cualquiera combinación de sus ordenes (personas, interacciones, instituciones, cultura, estructura social), de sus campos o subsistemas, y de sus niveles (micro, meso o macro). Así una crisis es un hecho social estructurado, algo que podemos reconocer como «...una instantánea temporal de una corriente de acontecimientos o una serie de tales instantáneas» (Jon Elster, 2003:13) pero, que se configura como un sistema de crisis. Toda crisis, está constituida por la secuencia estructurada de los eventos o acontecimientos que le dan origen y le suceden, pero también es un proceso que origina otros hechos sociales; que redistribuyen y transfieren desde sus relaciones los efectos de la crisis.

4.3. El saber de las crisis puede proceder del conocer sistemático de la ciencia o, de la experiencia del obrar de la praxis del vivir la crisis como agente, como paciente o como espectador. Esta última opción, del espectador comprensivo, es el pensar que organiza el conocer de la experiencia de la crisis, para expandir las oportunidades teóricas del conocer cognitivo, y dotarlo de sentido vital e histórico. Si el pensar es la clave del entendimiento del obrar de la praxis, «En este mundo al que llegamos, procedentes de ningún lugar, y del que partimos con idéntico destino, Ser y Apariencia coinciden» (Hannah Arendt, 2002:43), entonces, el pensar la apariencia de las crisis es la vidriera de sus modos de ser social. Por lo anterior, es que no es de extrañar que la comprensión de las crisis se haya realizado, casi siempre en occidente, desde una perspectiva dramática. La especulación teórica, ha tendido a traducir el drama de vivenciar la experiencia de la crisis en su fundamento. La noción de crisis suele llevar inscrita una sanción a priori de «mal de crisis» o de indeseabilidad de las crisis. Lo cual se evidencia en que la percepción de las crisis se termina por explicar y sentir como una «crisis de estimativa» (K. Mannheim, 1940; 1944). Admitiremos, sin embargo, que ante toda crisis se activan nuestros sentimientos, nuestras sensaciones y se desafía nuestra sensatez. En efecto, a veces, la rigidez del pensar teórico nos suele predisponer a una comprensión confrontacional de las crisis, ellas son por definición «nuestras enemigas», convirtiéndose así en un prejuicio teórico y en un «obstáculo epistemológico» (Gastón Bachelard,1988), que nos impide acercarnos al entendimiento de su realidad constitutiva, y de su papel 
en la historia. La mirada dramática de las crisis, se extiende también a su visión como las de un suceso casual o fortuito, del cual no somos responsables, sino tan sólo víctimas doloridas de los acontecimientos crísicos. En otra variante del drama de las crisis, éstas serían el hito demarcatorio de un final, que en su alternativa optimista, y como tal «situación límite» (K. Marx, 1968), las crisis abrirían paso hacia un anunciado devenir promisorio. Sin embargo, el sesgo ideológico utopista, más allá de la transición que la mayoría de nosotros anhelamos hacia una buena sociedad, ha jugado una mala pasada a la comprensión de las crisis; al concebirlas como «ruta crítica» obligada. En el progresismo utopista, la agudización de las crisis abriría la llave de paso al flujo de la necesidad histórica hacia nuestra liberación definitiva de la «coerción de los medios externos» (Karl Marx, 1962). No obstante, la liberación no dice nada de lo que debiera respecto de la libertad. Tal y como evidencia la Historia, de esas crisis fenomenales que son las revoluciones, éstas concurren siempre con la eclosión de las violencias, y el despliegue de su paso cruento y doloroso, trae siempre de la mano el costo odioso de los limitantes de la libertad. Sería brillante que el genio humano pudiese inventar una revolución social no violenta que, junto con instalar la justicia distributiva, amplificara la libertad de las personas y sus asociaciones; garantizando con ello la sustentabilidad social permanente. Pero, al menos hasta ahora, no se avizora aquel toque divino.

Quizá como conclusión provisional, habría que decir aquí que no parece existir algo así como el cambio crísico; el cual — nos parece- constituye sobre todo un mito sociológico. Las evidencias empíricas e históricas disponibles no son suficientes para validar la afirmación de que, ante una modalidad aguda de crisis particular y sistémica, el cambio crísico desencadene y explique la superación (aufheben), de un tipo de sociedad «inferior» por una de tipo «superior». Es posible que ni siquiera explique algún grado de «progreso necesario». Más bien, la mirada atenta al entorno limitado de nuestras propias biografías y las crisis, sería suficientemente elocuente para avalar la idea de que las crisis siempre nos parecen ser «pájaros de mal agüero» (lo cual refuerza nuestras visiones dramáticas). Si queremos ser ecuánimes, podríamos sostener a modo de hipótesis, que al menos existe tanta probabilidad de que una crisis, suficientemente intensa y duradera, conduzca a una debacle como a un remanso sociales. Sin embargo, con la proposición enunciada queda abierta la interrogante siguiente: ¿De qué depende que se dé una alternativa u otra? Como la «convergencia de intereses» - en un campo crísico- no es tarea sencilla; toda respuesta a las alternativas de la post crisis dependen del contexto de la acción, y de la ética de sociedad prevaleciente. Por otra parte, no existe inevitabilidad histórica de alguna novedad implícita en la manifestación crisica. Las crisis no entrañan el «misterio dialéctico» de su propia destrucción mediante lo anticrísico. Tal como una revolución puede estar inspirada en propósitos conservadores o de restauración de algún 
ancien regime (o traerlos como consecuencia); las crisis pueden (y, por desgracia, suelen) inducir regresos, estimular violencias y abrir paso a nuevos totalitarismos. De hecho, toda guerra ha sido precedida de alguna forma de crisis, y las crisis siempre han sido su desencadenante mediato. Nada esperanzador, a decir verdad.

4.4. En medio de toda crisis, saber y comprender de la crisis se ven restringidos, ya que no existe ni el espacio (restricción de lugar) ni el tiempo (restricción de mercado) para construir un saber racional crítico de las crisis y su comprensión. En el occidente capitalista contemporáneo, son los mercados los que asignan la distribución del tiempo social destinado a la investigación para el conocer de las crisis. Si solamente importa «salvar la coyuntura», el conocimiento técnico — que actúa sobre los medios y agrega valor económico-, tendrá el exclusivo privilegio de ocupar el lugar de todo el saber sobre las crisis. La teoría social de las crisis resulta así pospuesta, cuando no sojuzgada por el mercado. La mirada comprensiva, aquella previa al saber de la ciencia sobre las crisis, se atiene a pequeños intersticios académicos; exclusivos y algo diletantes. La comprensión, que sucede al saber, queda en la mayoría de los casos abiertamente cancelada. La sociología suele verse atrapada en este interludio de inmediatez analítica; restringiéndose al comentario ligero del evento oportuno. Con lo cual se ve reafirmado aquel aspecto de la crisis del saber de las ciencias sociales que lo localiza en la calidad de sus teorías. Se produce así, un desplazamiento de la vita contemplativa por la vita reactiva. Vivimos reaccionando ante las crisis; sin que podamos acceder al conocer de las crisis para su reflexión crítica en el comprender. Por lo anterior, es que afirmamos aquí que la sociología $-\mathrm{y}$ las ciencias sociales en su conjunto-, enfrentan una crisis de sincronía teórica; respecto de su solvencia científica y reflexiva para proporcionar el saber y el comprender de las crisis de su tiempo en su tiempo. Esta crisis se vivencia como ineludible, y su actual inevitabilidad parece provenir de su enganche dentro del proceso tendencial hacia una crisis fundamental de insustentabilidad social global. No obstante, la crisis de las disciplinas sociales es, asimismo, una crisis histórica fundacional, que en cada sociedad di novo surge iterativa respecto de las crisis y del tiempo no crísico; dado que la sociedad misma se nos aparece desde sus orígenes como una realidad histórica de recurrencia crísica. Dicho entrampamiento diacrónico de la sociología $-\mathrm{y}$ las ciencias sociales en su conjunto- promueve obstáculos al pensar racional crítico del saber; a su necesario distanciamiento teórico, situado en la frontera ensimismada del ser social (Lo que se nos aparece como la paradoja de vivir el pensar asociativo desde la desvinculación). A consecuencia de lo mismo, se introduce lo que denomina el «dilema de Ortega»: ¿somos espectadores o actores en las crisis? Saber si estamos dentro de la crisis o fuera de ella, si podemos apartarnos para el ejercicio del pensar, invocando aquella actitud de «compromiso y distanciamiento» que nos recomendaba 
Norbert Elías (1990), constituirá sin duda una condición fundamental de la comprensión de las crisis contemporáneas. Sin embargo, también nos parece, que el propósito de la comprensión, desde la libertad del pensar contemplativo, no puede ser sino el preludio para la acción desde una vita activa.

4.5. No podemos dejar de tener en cuenta, por otra parte, que la amplia experiencia de crisis vividas ha permitido la acumulación de un vasto conocimiento empírico asistemático; que se expresa como sentido común de las crisis. Sentido común, cuyo «realismo ordinario» digamos también, es siempre cambiante desde su validez, suele ser ubicuo cuando no derechamente equívoco en sus presunciones, y no siempre es en si garantía de una perspectiva socialmente nutricia de las crisis. De lo que si puede prevenirnos el sentido común, es de evitar el imperio de la racionalización implacable y del totalitarismo de la ciencia. Así, más que una teoría social de las crisis, se ha venido conformando un estado del arte de las crisis que hace referencia, junto a otros, a dos aspectos particularmente relevantes respecto del como encaramos las crisis: $1 .^{\circ}$ Las crisis deben ser amortiguadas cuanto antes; a fin de aminorar los costos del desbocamiento de sus amenazas; cualquiera ellas sean y, 2. ${ }^{\circ}$ Debemos desmantelar las crisis desde sus componentes desagregados. Desde luego, sería difícil argumentar en contra de la idea de buscar reducir los efectos negativos o penosos de cualquier crisis. Más fácil resulta argumentar en contra de una visión «cosista», que entiende a las crisis como aparatos desmantelables, de componentes intercambiables o sustituibles; descontextualizados de una realidad social que está ineludiblemente reedificada y comunicada. La incorporación ideológica en el uso práctico de los aspectos señalados, junto a otros de tono similar, han actuado como impedimentos ciertos para un conocimiento relacional y sistemático, así como de una comprensión sistemática de las crisis, y de sus modos adecuados de «regularlas», «transformarlas» o vérnoslas con ellas. En efecto, y como hipótesis de trabajo abierta, puede sostenerse que: la mayoría de las «soluciones» a las crisis de nuestro tiempo tienden a ser erráticas, a destemporalizar y trasladar las crisis de unos ordenes sociales a otros, de unos niveles sociales a otros, a desplazar las crisis desde los niveles de sociedad-país a los internacionales y globales, o viceversa, y sobre todo a reducir oportunidades y capacidades de libertad de las personas individuales y asociativas. Hay que recordar aquí, además, que no siempre los amortiguadores evitan la caída. Las soluciones nunca son meramente tecnológicas ${ }^{11}$ (medios) —lo son en cierta medida-, y siempre involucran la definición de los fines. Se suele desatender, flagrantemente, el objetivo social de la transformación de toda

11 Tristemente patente a consecuencia del aún incontrolado desastre petrolífero del Golfo de México, protagonizado por la British Petroleum; así como de su equivalente catastrófico - totalmente desinformado en occidente- ocurrido en las costas de Nigeria. 
crisis que es el de lograr un mayor incremento neto ${ }^{12}$ de la sustentabilidad social como resultado de la intervención de crisis.

\section{Provisiones interpretativas del saber social de las crisis: Lo crisico de las crisis}

5.1. Tal como los conflictos sociales solamente aparecen en la naturaleza con las asociaciones humanas, capaces de conocer y experienciar la conciencia del conflicto desde su praxis cultural; así también las crisis son fenómenos exclusivos de las sociedades humanas ${ }^{13}$. Ello posibilita formas del vivir en la experiencia de crisis y los conflictos, así como de sus interpretaciones, que pueden observarse como distinciones culturalmente diferenciadas. Las crisis, como los conflictos, aparecen en la historia de todas las sociedades como eventos recurrentes. Empleando una extensión de sentido, inspirada en Leo Strauss (2005), podríamos decir que comprendemos las crisis como problema perenne de la sociedad.

5.2. Así como el nivel de conflictualidad ${ }^{14}$ de una sociedad puede estar o no relacionado con sus tendencias crísicas, ninguna relación posible parece poder establecerse como condición de necesidad histórica que permita deducir, de los conflictos o de las crisis, la disolución o extinción de una sociedad particular. Las únicas situaciones, en las cuales la insuficiencia social podría llegar a ser eventualmente terminal o conclusiva, pudiera surgir de hechos cumulativos y complejos que lleven a la reducción histórica irreversible, de coherencia y eficacia, de aquella institucionalidad que promueve la expansión de su asociatividad. Sólo tenemos antecedentes fragmentarios que sugieren hipótesis posibles de casos de reducción histórica irreversible, por ejemplo, en algunas sociedades precolombinas Mayas (Guatemala y México actuales) o, más nítidamente, en los Rapa Nui de la Isla de Pascua en el Pacifico Sur (Chile actual). En cambio, existe abundante información histórica referida a la persistencia de las crisis de insuficiencia social. A condición de ellas, la sociedad ve reducida sus capacidades para reproducirse creativamente, mediante nuevos arreglos institucionales, que restauren, restablezcan o renueven permanentemente su convivencia, en la cooperación y asociatividad; desde sus propias articulaciones de libertad. No obstante, las

12 ¿Cuánto más sustentable es la sociedad a consecuencia de la crisis resuelta?

13 Parece difícil aún demostrar que «animales sociales no humanos» realicen la distinción de conflictos sociales y crisis desde el lenguaje y en el pensamiento.

${ }^{14}$ Adoptamos aquí la distinción señalada por Ramón-A Gutiérrez P. (2008) en Diálogos sobre paz y conflicto en América Latina. Universidad para la Paz, Santiago de Chile-San José C.R. Que en su página 8 señala: «Preferimos la expresión "conflictualidad" para prevenirnos de la connotación usualmente negativa incorporada en el término "conflictividad"». 
sociedades parecen evidenciar con mucha mayor frecuencia el ciclo insuficiencia-estagnación que el ciclo suficiencia-creatividad.

5.3. Cada vez que una sociedad enfrenta una situación crísica, que amenaza su viabilidad histórica de reproducción recreativa, desde su propia organización, y no primariamente desde su entorno natural, estamos frente a una situación de insustentabilidad social. De tal suerte que, las persistencias y acumulaciones de crisis, en los diversos ámbitos del sistema, o entre distintos sistemas sociales de personas en curso de interacción ${ }^{15}$, comunican una señalética sintomática de procesos de insustentabilidad social en curso de interrelación desigual; ya sean estos intrasocietales o intersocietales. El ajuste de arreglos sociales, organizados en torno a mercados supuestamente autorregulados, por un número significativo de países; ha contribuido a facilitar la transmisión globalizada de las crisis y sus «soluciones». Así, la expansión del involucramiento, de los procesos de insustentabilidad social, en interrelación creciente en el plano global o mundial, aparecen como una situación de reducción histórica, en la cual pueden observarse unos atributos identitarios, aunque no obligadamente convergentes; que asimismo pueden interpretarse como signos evidentes de la manifestación de un proceso tendencial hacia una crisis fundamental de insustentabilidad social global. En consecuencia, sostendremos aquí a modo de tesis, que:

La sociedad humana se nos aparece, desde sus orígenes, como una realidad histórica de recurrencia crisica. Desde nuestra contemporaneidad de globalización tardía, parecemos estar ante una reducción histórica, que se expresa como proceso tendencial hacia una crisis fundamental de insustentabilidad social global; cuyo principal atributo es que esta vez (algunos) lo sabemos, y por lo cual aparece trascendentalmente interpelada nuestra voluntad de querer para ser con otros.

No es, por ejemplo, el «cambio ambiental global» el que induce la crisis social sino, por el contrario, es la crisis de insustentabilidad social la que desencadena los procesos de aceleración de la crisis ambiental global. De igual manera sucede con la actual «crisis financiera del capitalismo global»; donde son marcadamente evidentes, los basamentos de dicha crisis en la ética de sociedad prevaleciente. La diferencia entre una óptica y otra puede, a no dudarlo, significar la diferencia entre la catástrofe social de cumplir las profecías apocalípticas, y la transformación civilizatoria de la humanidad. ¿Qué elegiremos desde nuestras posibilidades de poder? ¿Qué elegirán, quienes deciden por nosotros, desde sus posiciones de poder?

La exteriorización frecuente, en el plano de la conciencia discursiva de la tendencia señalada, pone el centro de la responsabilidad de dichos procesos, en la ausencia de un pensamiento relevante y consecuente con la signi-

${ }^{15}$ Habida cuenta de que: «No son las sociedades las que entran en interacción entre sí, sino que lo hacen solo los individuos» (Jon Elster, 2006:282). 
ficación de dicha eventual insustentabilidad social global, y consiguientemente, interpela la ética de sociedad; en cuanto expresión histórica concreta del obrar moral de las sociedades particulares, y de éstas en sus cursos de interacción en el contexto de una presumible buena sociedad global.

5.4. Tal como hemos señalado, la naturaleza no manifiesta, no enfrenta, ni sufre crisis alguna. Toda crisis es siempre y únicamente una situación particular en y desde la sociedad humana, toda crisis es propiamente humana; en sus causas y en sus consecuencias. Las vinculaciones existentes entre «crisis alimentaria» y "crisis energética», son un buen ejemplo de causas y consecuencias sociales de las crisis. Las situaciones de crisis aludidas, no se atienen en su causalidad a una escasez natural de recursos naturales; sino a una cultura de consumo y su correspondiente sistema tecno económico, que han creado dicha escasez. La escasez no es consecuencia espontánea de ningún sistema natural; sino que es un atributo de valoración culturalmente asignado. Por ello, el «problema de la economía» está fundamentalmente errado al suponer que la escasez es un «problema originario», que así visto, pareciera provenir de algún castigo divino por malversación de recursos naturales en el Edén de todo sistema económico.

5.5. El conocer y experienciar la conciencia de la crisis se realiza desde la propia praxis de la persona individual y de la persona asociativa. Ello posibilita la situación cultural en la cual la crisis puede no ser percibida en parte, puede no ser percibida oportunamente en su tiempo, puede ser percibida como un drama que nos enfrenta como enemigos, tal como señalábamos anteriormente o, y esto sí que es un drama auténtico, la crisis puede no ser percibida del todo. Sin embargo, al menos teóricamente, la mayor parte de las crisis pueden ser previstas, y en no pocos casos acotados se pueden también predecir; a condición de que exista un mecanismo social institucionalizado que haga sonar la alarma ante las reducciones significativas de sustentabilidad social. Así, por ejemplo, sabemos que los mercados financieros funcionan como un sistema caótico, cuyo direccionamiento obedece solamente a la rentabilidad del capital, creando - entre otros - los efectos de volatilidad de la inversión. En consecuencia, siempre serán previsibles las «crisis financieras», habida cuenta de que ellas siempre existirán; en tanto prevalezca una desregulación institucional de los mercados en detrimento de la sustentabilidad social. Entonces, más allá de la ingenuidad, parece pertinente preguntar: ¿Por qué, luego de la «crisis asiática», y sus múltiples homólogas que le han sucedido, se insiste todavía en la autorregulación de los mercados financieros? ¿Tendrá algo que ver con la afirmación de que: «Una economía de mercado supuestamente autorregulado puede generar un capitalismo mafioso - y un sistema político mafioso-, preocupación que por desgracia es ya algo muy real en algunas partes del mundo»? (Joseph E. Stiglitz, 2007:17). Como decíamos, ante una crisis de insuficiencia social, 
cualquiera sea su núcleo organizador y mecanismo generador, aparece inmediatamente interpelada la ética de sociedad prevaleciente.

5.6. Reiteraremos aquí que toda crisis obedece en sus causas, consecuencias y reflexividad, a una particularidad histórica concreta; la cual siempre se manifiesta en detrimento de la libertad. Para señalar a la vez que, la libertad misma es siempre la condición de su solución posible. Esto llevaría a reescribir la referida sentencia de Marx, en el sentido de que: ante una crisis, lo que buscamos, es liberarnos de la coerción de los medios y modos de ser internos del ser social, y que se externalizan como obstáculos a su libertad. Aquí radicaría el principal problema de solución de las crisis: ¿cómo amplificar la libertad desde un proceso que tiende a restringirla? De hecho, como observamos a diario, la mayoría de las «soluciones» a las crisis, tienden a ser restrictivas de la libertad. Esta interrogante no es inocente, puesto que las soluciones de las crisis de sustentabilidad quedan delimitadas por la definición de los fines de la sociedad. Toda crisis, en consecuencia, al reducir la viabilidad social del sistema, amplifica el abanico de restricciones inmediatas. Así, en general, si el ser social es prisionero de una libertad negativa abrumadora, existen pocas posibilidades para que la automía de su agencia, desde una ética de libertad positiva (Isaiah Berlin, 1974), pueda asumir la reorientación de la sociedad hacia su propia sustentabilidad. El corolario aquí es que en tanto una sociedad es más abierta, libre y justa pareciera proporcionar mayores oportunidades de reorganización del sistema social ante las crisis. Los «derrumbes»-económicos, políticos, religiosos, o aun de la sociedad como sistema-, atribuibles a crisis cumulativas agudas de larga maduración, en realidad son bastante más posibles, y quizá también más probables, en sociedades cerradas. Estas últimas, asimismo, limitan las oportunidades de interacción nutricia con otras sociedades ${ }^{16}$, y ambientes naturales en el curso de su trayectoria. (¿Nos dice algo a este respecto el derrumbe de la URSS?; ¿El derrumbe de la eufemística «Alemania Democrática», o de las Polonia y Albania comunistas?)

5.7. Decíamos que hemos experimentado crisis desde que nos constituimos en sociedades. En efecto, como personas socialmente situadas, todos somos tomadores de decisiones y captadores de riesgos crísicos. Independientemente de cuál sea su núcleo organizador, o su fuente originaria - las cuales pueden coincidir o no-, todas las crisis de la sociedades humanas han sido, y siguen siendo, crisis de sustentabilidad social. Con lo cual, la interrogante evaluadora de toda sociedad será: ¿cuánta sociedad tenemos y necesitamos para convivir en la libertad de nuestra potencia de ser? Sin embargo, toda crisis es desigual en sus causas, así como en sus efectos e impactos sociales. Toda crisis tiende a incrementar la desigualdad social, y

${ }^{16}$ La restricción y vigilancia, que realiza el Estado respecto del uso que de las nuevas TICs e Internet puedan hacer las personas, en tanto ciudadanos, es un claro ejemplo de esto. 
a reestructurar la distribución del poder social. Por ello es que la crisis modifica nuestras atribuciones de poder en la toma de decisiones, y los tipos e intensidades de riesgos son captados por las personas bajo condiciones de mayor desigualdad.

5.8. Si toda crisis surge en la sociedad, ya que hemos señalado que no hay crisis fuera de la sociedad humana, entonces, toda crisis tiene una dimensión fundamental de expresión comunicacional ${ }^{17}$ a través del lenguaje humano. Particularmente, porque: en las crisis lo que está en crisis es el ser social en sus relaciones, y lo crísico de la crisis, es la insuficiencia del modo de relacionarse las personas entre sí, y con los objetos de su cultura, para sustentar su asociación. Las implicancias ontológicas de esta afirmación se hacen evidentes. Ya que, «El asunto esencial acerca de los seres humanos es que el lenguaje les da la capacidad de representar. Por lo demás, pueden representar no solo que es un asunto, sino que es lo que fue, lo que será y lo que podría llegar a ser. Todavía más espectacular, es que pueden mentir. Pueden representar algo como si hubiera sido aún cuando crean que no lo es» (John Searle, 2006:60). Es el lenguaje el que permite pensar las crisis como objetos sociales, asignarles un sentido, y elaborar un mensaje comunicable mediante su imagen conceptual. La crisis tiene su estructura, y correlativamente los actores sociales, en tanto «observadores relativos» (John Searle, 1995), elaboran un concepto de crisis. Si las crisis forman parte de lo real, el concepto de crisis que se elabora no existe con independencia de la crisis, y este mismo concepto es constitutivo de las crisis, de su estructura y devenir. De la comunicabilidad de un concepto consensual de crisis puede surgir la posibilidad de una solución no crísica de las crisis. La reconceptualización de la crisis puede, a su vez, abrir opciones alternativas de viabilidad social; desde la argumentación de un nuevo arreglo organizacional e institucional para los agentes involucrados. La comunicación debiera contribuir, decisivamente, para alcanzar un restablecimiento de la suficiencia de las relaciones sociales en crisis, construir un balance social apropiado, y conformar una instancia dialógica estructurada para la transformación de la crisis en una oportunidad socialmente nutricia. En efecto, la comunicación de la sociedad es una póliza de garantía al portador cuando surgen las crisis. Por el contario, una descomunicación persistente de amplios sectores de la población social, la que con frecuencia incluye la abierta incomunicación e invisibilidad de otros (autoexcluidos, marginados, segregados culturales, inmigrantes, etcétera), son el escenario ideal para la expansión del efecto multiplicador de las crisis en sus diferentes formas. Y, tal y como evidencia la Historia, siempre es factible la superación de las crisis; mediante la construc-

${ }^{17}$ Desde luego que: «El término comunicación debe reservarse a la interrelación humana, al intercambio de mensajes entre hombres, sean cuales fueren los aparatos intermediarios utilizados para facilitar la interrelación a distancia». Antonio Pasquali. (1990). Comprender la comunicación. Monte Ávila Editores, Caracas. 
ción de futuros inclusivos posibles. En efecto, siempre en ellos hay involucrado el trazado de caminos que conducen a alianzas para su transformación (umbau). De ella, surgen nuevos escenarios problemáticos que, eventualmente, darán origen a nuevas crisis. Por desgracia, la Historia también enseña que las «soluciones finales» a ciertas «crisis», se han intentado - y nada indica que no seguirán intentándose- $\mathrm{y}$, en muchos episodios, tan sólo por un reducido «casi», no llegaron a consumar sus resultados perversos. No pueden dejar de conmemorarse aquí — entre una larga y vergonzosa listalos ejemplos emblemáticos de genocidio en la Alemania Nazi, en BosniaHerzegovina, y en Rwanda.

5.9. Las crisis tienen algo que hacer entre nosotros; no son casuales, son causales, y están aquí porque - algunos de nosotros - las hemos provocado. Las crisis son la montura del jinete. Vivimos entre las crisis y por ellas también viviremos. La conciencia de responsabilidad, por parte de los agentes de la crisis, resulta entonces esencial al definir la asignación de los costos de su solución. Ya que, el peligro de escalada de las crisis siempre reside en sus grados de injusticia. Las crisis ocupan un papel en la historia, y una función en la sociedad, que son dependientes de los atributos de cada una de ellas, y que según parece, solamente pueden reconocerse ex post. En el fondo de toda crisis, reside la pregunta: ¿vale la crisis el mantenernos asociados? Especialmente ya que, en toda crisis, la tensión entre la persona individual y la persona social o asociativa se evidencian. En algunas crisis, las deformaciones polarizantes, tienden a la preponderancia del individualismo; en otras lo hace el colectivismo. Contamos con evidencias contundentes, por todos conocidas, de las consecuencias más extremas, nocivas e impactantes de ambas tendencias.

\section{Provisiones, de último momento, para instigar el pensamiento sobre las crisis}

El spectaculum de las crisis contemporáneas es amplio, diverso, persistente, cada vez más intenso, y nada ajeno. El tiempo y el espacio de crisis, en nuestra globalización tardía, parece expandirse, y las crisis se enlazan haciéndose más complejas; en sus causas y soluciones posibles. No parece sino refrendarse la tendencia, desconcertante en principio, hacia una insustentabilidad social global. Vivimos una crisis de relacionamiento; ya que hemos perdido el sentido de comunicar quiénes somos, y el propósito humano de nuestros vínculos como personas. Las crisis parecen reducirse históricamente, a un problema de definición de fines, específicamente, sobre cual tipo de asociación será capaz de mantenernos juntos para desplegar nuestras potencialidades de ser en libertad. En una época en que vivimos bajo el imperio 
conformista de los mínimos ${ }^{18}$; parece latente la perentoria irrupción de los reclamos por la posibilidad de los máximos. De esta forma, el imperativo de una justicia global queda señalado como el eje cardinal, generador y ordenador, de una Sustentabilidad Social Global. Esta crisis fundamental de insustentabilidad social global, aparece como la crisis primordial de nuestro mundo actual; como la madre de todas las crisis. Es nuestro fantasma errante que recorre el planeta desde occidente. Sin embargo, desde nuestras particulares sociedades, ya en occidente ya en oriente, en el norte y en el sur, otorgamos sentidos distintos a esta crisis, y nos incorporamos a ella en tiempos diversos. El diálogo intencional de los sentidos de la crisis, ameritaría así también encontrarse en su tiempo. Todo nos conduce, sin embargo, a advertir la carencia de un pensar y repensar las crisis desde la sustentabilidad de las relaciones sociales humanas. Quizá, ello nos remite a una solapada crisis general del pensar. Pero, una crisis del pensar es una crisis de lo humano en lo que tiene de distintivo. De tal manera que revertir esta «crisis fundamental» implicará esta vez, una transformación humana de lo humano. Donde, «Lo más esencial en la transformación del hombre es la transformación de su facultad de pensar y de querer» (Karl Mannheim,1984:101).

Quizá porque las crisis sociales tienen en común con las crisis personales, el que no sabemos bien cómo se originan hasta que sentimos sus efectos aflictivos, es que no siempre tenemos dispuestos nuestros sentidos para aquilatar sus causas, y visualizar cuáles son nuestras opciones para salir de ellas expandiendo nuestras posibilidades de ser desde el pensar. Pero la maquinaria crísica está en marcha, y las interrogantes abiertas que provoca y apremian son muchas, entre otras: ¿No es acaso ésta una crisis de sobrevivencia en la convivencia?; ¿Será posible la convivencia en la sociedad global crísica sin el pivote de una justicia global?; ¿De cuánto tiempo disponen las sociedades humanas para producir una convivencia socialmente sustentable?; ¿Acaso, queremos seguir conviviendo en una sociedad global crísica?

\section{REFERENCIAS BIBLIOGRÁFICAS}

Albert, Hans (2002): Razón crítica y práctica social. Ediciones Paidós, Barcelona. Arendt, Hannah (2002): La vida del espiritu. Ediciones Paidós, Buenos Aires.

Arendt, Hannah (2005): De la historia a la acción. Ediciones Paidós, Buenos Aires. Bachelard, Gastón (1988): La formación del espiritu científico. Contribuciones a un psicoanálisis del conocimiento objetivo. Editorial Siglo Veintiuno, México.

Bunge, Mario (1999): Las ciencias sociales en discusión. Una perspectiva filosófica. Editorial Sudamericana, Buenos Aires.

Elias, Norbert (1990): Compromiso y distanciamiento. Ediciones Península, Barcelona.

${ }^{18}$ Como los inalcanzados y todavía distantes «Objetivos de Desarrollo del Milenio». 
Elster, Jon (2003): Tuercas y tornillos. Una introducción a los conceptos básicos de las ciencias sociales. Gedisa editorial, Barcelona.

Elster, Jon (2006): El cemento de la sociedad. Las paradojas del orden social. Gedisa editorial, Sevilla.

Lélé, S. M. (1991): «sustainable Development: a critical review». World Development, n. ${ }^{o} 19$ (6). Pergamon Press, London, pp. 607-621.

Mannheim, Karl (1984): El hombre y la sociedad en la época de crisis. Editorial Leviatán, Buenos Aires.

Marx, Karl (1962): Manuscritos económico-filosóficos de 1844. Editorial Grijalbo, México.

Marx, Karl (1968): El Capital. Fondo de Cultura Económica, México.

Morin, Edgar (1978): «El hombre por explicar». En Mazingira. n. ${ }^{\circ}$ 6, pp. 54-60.

Pereira, Gustavo (2004): «Virtudes cívicas procedimentales, democracia participativa y educación ciudadana». En Areté. Revista de Filosofía. Vol. XVI, n. ${ }^{\circ}$ 2, pp. 243 a 281 .

Pereira, Gustavo (2007): ¿Condenados a la desigualdad extrema? Un programa de justicia distributiva para conjurar un destino de Morlocks y Eloi. Centro de Estudios Filosóficos, Políticos y Sociales Vicente Lombardo Toledano, México.

Sen, Amartya (2000): Desarrollo y Libertad. Editorial Planeta, Buenos Aires.

Singer, Peter (2007): How are we to live? Ethics in an age of self-interest. Oxford University Press, Oxford.

Stiglitz, Joseph E. (2007): «Prologo». En Polanyi, Karl. La gran transformación. Los orígenes políticos y económicos de nuestro tiempo. Editorial Fondo de Cultura Económica, Buenos Aires.

Strauss, Leo (2005): ¿Progreso o retorno?. Editorial Paidós, Buenos Aires.

Vandenberghe, Frédéric (2007): «Une ontologie réaliste por la sociologie: systéme, morphogenése et collectifs.» En Social Science Information. Vol. 46, n. . 3, pp. 487 a 542 . 